\title{
Anticonnective tissue and other antitissue 'antibodies' in the sera of patients with coeliac disease compared with the findings in a mixed hospital population
}

\author{
N. Williamson, P. ASQUith, P. L. STOKeS, A. W. JOWETT, AND \\ W. T. COOKE
}

From the Department of Experimental Pathology, University of Birmingham, The Queen Elizabeth Hospital, Birmingham, and The Nutritional and Intestinal Unit, The General Hospital, Birmingham

SYNOPSIS Serum IgG specificities directed against various components of basement membrane and reticulin have been described, and their incidence in 138 patients with coeliac disease has been compared with that in 110 hospital inpatients, 100 normal blood donors, and 1441 other patients. A wide variety of antitissue specificities were observed but only a few appeared to be of any significance. The 'antireticulin' specificities have been subdivided into different groups according to their distinctive histological staining patterns. Specificity directed primarily against endothelial basement membrane was found most frequently in the sera of patients with hiatus hernia $(35 \%)$ or coeliac disease $(22 \%)$. The same specificity was also observed in patients with myasthenia gravis and to a lesser extent in Crohn's disease and in a mixed group of patients with unspecified organic gastrointestinal disease. An epithelial basement membrane reactivity was found in patients with rheumatoid arthritis but only rarely in other conditions. Staining of perivascular connective tissue represented a third type of 'antireticulin' specificity. It was found only rarely, although in coeliac disease this reactivity was found more frequently in combination with other connective tissue specificities.

Seah et al (1971a) first reported the detection of an IgG autoantibody directed against certain connective tissue components in $36 \%$ of patients with adult coeliac disease and in $17 \%$ of patients with dermatitis herpetiformis. Similar findings were published by Alp and Wright (1971). The reactivity appeared to be directed against reticulin and was demonstrated in between 54 and $74 \%$ of children with coeliac disease (Seah et al. 1971b; Alp and Wright, 1971; von Essen et al, 1972; Brown et al, 1973). Initially this specificity was thought to be characteristic of sera from patients with coeliac disease (Seah et al, 1971a) but subsequently it was shown to occur in $25 \%$ of patients with Crohn's disease and to a lesser extent in other diseases also (Alp and Wright, 1971; Seah et al, 1973). The reactivity was found in the sera of patients with coeliac disease more frequently in those on a normal diet than in patients maintained on a gluten-free diet (Alp and Wright, 1971; Seah et al, 1971b; von Essen et al, 1972). In six children rechallenged with

Received for publication 17 November 1975 gluten, Alp and Wright (1971) recorded the development of reactivity in four and persistence of reactivity in a fifth, and this appeared to correlate with the detection of antibodies to gluten fraction III. Cross-reactivity with gluten was considered a likely explanation for these findings (Seah et al, 1972). However, the formation of similar staining patterns with sera from patients with Crohn's disease suggests an alternative mechanism which may be no more than a non-specific reflection of tissue damage.

Initially, Seah et al (1971a) described three types of staining pattern in the sera of patients with coeliac disease (although the frequency with which each occurred was not stated), but subsequently they did not differentiate between these (Seah et al, 1971b). The overall reactivity regardless of minor differences in pattern appears to correspond to the antireticulin specificity described by Alp and Wright (1971), von Essen et al (1972), and Brown et al (1973). Also it seems likely that the reaction of basement membrane found in the sera of patients with selective IgA deficiency and coeliac disease (Ammann and Hong, 1971) is of similar specificity. 
Subsequently, Rizzetto and Doniach (1973), in the course of examining 8000 different sera, described five staining patterns which they assumed to be distinguishing distinct antigens of intra- and extracellular components of mesenchyme. The overall and relative incidence of these antibodies was established in 3628 sera from various diseases, including coeliac disease. However, they did not report the relative incidence of each staining pattern in relation to the different disease categories studied. It is, therefore, still uncertain whether the increased incidence of 'antireticulin' specificity seen in patients with coeliac disease is associated with an increase of one particular pattern or whether it is due to an increase in all varieties described.

The purpose of this communication is to describe in detail, and to assess the incidence of the various connective tissue specificities found in adults with coeliac disease compared with the incidence of these specificities found in a mixed hospital population.

\section{Material and Methods}

\section{PATIENTS STUDIED}

Two hundred and seven serum samples were obtained from 133 adult patients with coeliac disease, all having the characteristic jejunal biopsy appearance. Fifty-nine samples were from 42 patients on a normal diet and 148 samples from 91 patients on a gluten-free diet, including eight patients who were studied before and after gluten withdrawal. Repeat samples were examined as a control of the method. Only one serum sample was used from each patient in assessing the incidence of the antibodies.

Control sera were obtained from (a) 100 normal blood donors, and (b) 110 hospital inpatients chosen from the medical wards matched for age and sex with the first 110 adult coeliac disease patients studied, only patients suffering from coeliac disease, hiatus hernia or myasthenia gravis being excluded.

In addition, 1441 patients with a variety of conditions were studied. First, there was a further group of intestinal diseases including Crohn's disease (29), ulcerative colitis (8), hiatus hernia (94), and other miscellaneous gastrointestinal diseases (31). Then among a group of connective tissue diseases were rheumatoid arthritis (634), systemic lupus erythematosus (30), myasthenia gravis (20), and other miscellaneous connective tissue diseases (182). This last miscellaneous group included patients with scleroderma, psoriatic arthropathy, ankylosing spondylitis, polyarteritis nodosa, and dermatomyositis. Patients with liver disease were divided into two groups, chronic active hepatitis (32) and other miscellaneous liver diseases (78). The remaining 303 sera were grouped together under the heading miscel- laneous disorders and came from six broad diagnostic groups based on the system involved: cardiovascular disease (84), respiratory disease (37), neurological disease (77), renal disease (60), haematological disease (23), and endocrine disease (22).

The serum specimens were randomized and coded before being tested and were examined without knowledge of the clinical diagnosis.

\section{IMMUNOFLUORESCENCE STUDIES}

A standard indirect fluorescent antibody method was used (Nairn, 1969). Antitissue reactivities were sought using the patients' serum (diluted 1 in 5), a fluorescein-conjugated monospecific sheep antihuman IgG antiserum, and sections of fresh rat kidney, stomach, and salivary gland. Occasionally sections of human tissue obtained at necropsy were substituted. The antihuman IgG serum was raised in sheep and was conjugated with fluorescein isothiocyanate (BDH isomer I) using essentially the method of Nairn (1969). A Reichert Fluorpan microscope was used to examine the stained sections. Specificity of the immunofluorescent staining was checked by including a known positive and negative serum with each test.

\section{Results}

A number of different staining patterns were encountered and these are considered in three groups: (1) 'antireticulin' reactivity, (2) well recognized antibodies to cellular and subcellular components, and (3) other less well recognized reactivities. Details of these groups are outlined below.

\section{GROUP 1 'ANTIRETICULIN' REACTIVITY}

Staining of reticulin or reticulin-like fibres of connective tissue was obtained when using sera from patients with a variety of differing conditions. If tissues rich in reticulin, such as, for example, spleen, were used then these different sera produced a very similar type of staining pattern (fig 1). If, however, other tissues such as kidney or salivary gland were used then differences between these reactivities became apparent, and it is on the basis of these differences that the following descriptions are made.

\section{Endothelial Basement Membrane Reactivity}

Rat kidney sections showed considerable staining throughout the nephron affecting basement membrane like structures. The glomeruli showed rather diffuse membranous staining whereas in the renal medulla the pattern appeared to be associated with the extensive capillary network (fig 2). 


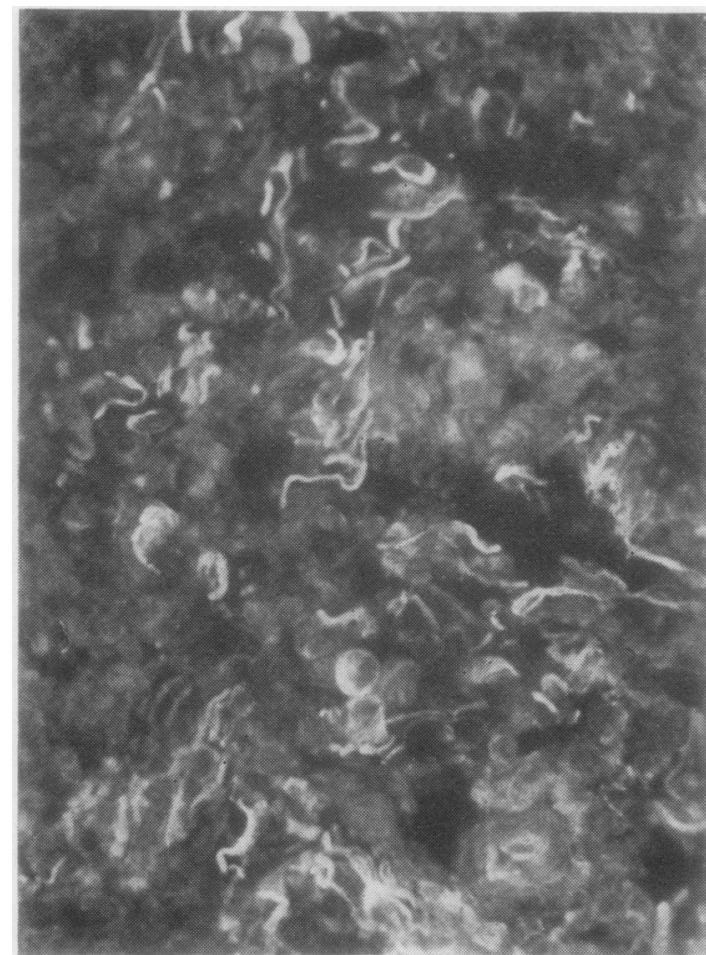

Fig 1 Staining of reticular connective tissue in human spleen. Rheumatoid arthritis serum. $\times 376$.

\section{Perivascular Connective Tissue Reactivity}

This type of staining pattern was characterized by reactions predominantly with the fine collagen and reticulin fibres in the loose perivascular connective tissue (fig 3). Although the staining of structures in and around the arterial adventitia represented the most distinctive feature, there was also staining of other tissues such as, for example, the loose connective tissue of the rat stomach submucosa. In the kidney a rather granular broken appearance was seen associated with the smaller vessels of the medulla (fig 4); however, the glomeruli were unstained. Occasionally the perivascular staining took the form of thick homogeneous bands formed around the vessels with reactivity to both fibres and ground substance.

\section{Epithelial Basement Membrane Reactivity}

A distinctive staining pattern reacting predominantly with the epithelial basement membrane of most glandular tissues was sometimes observed. In kidney sections only the epithelial lining of the glomerular tufts was stained (fig 5). In salivary gland there was some staining of duct epithelial basement membrane and also a unique reaction with the branching basal or basket cells (fig 6).

\section{'Glomerular Antibody'}

When sera from patients with chronic active hepatitis were reacted with kidney sections, the glomeruli were brightly stained. This reactivity was first described by Whittingham et al (1966) and they called it the 'glomerular antibody'. This reactivity gave an intricate staining of membranous and cellular elements (fig 7). There was also some membranous staining in other tissues, for example in salivary gland there was partial staining of the epithelial basement membrane which gave a rather broken appearance. However, the lack of staining of the basket cells distinguished this antibody from the epithelial basement membrane reactivity.

GROUP 2 WELL RECOGNIZED ANTIBODIES TO CELLULAR AND SUBCELLULAR COMPONENTS

The staining patterns for these antibodies have already been well described. Johnson et al (1965) described the smooth muscle antibody, Walker et al (1965) described the mitochondrial antibody, Taylor

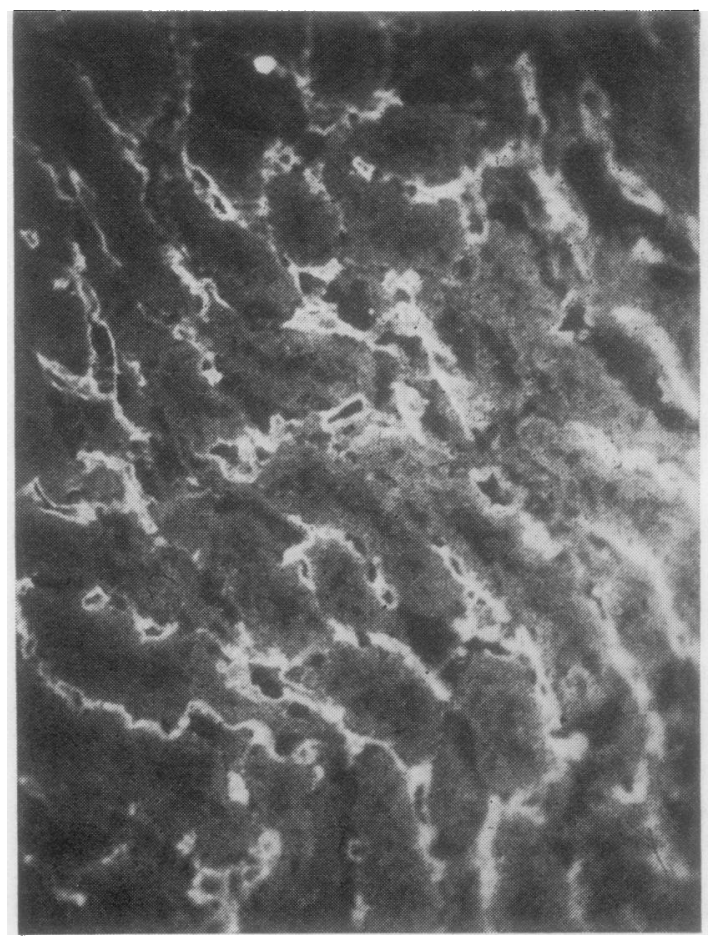

Fig 2 Capillary network staining in renal medulla produced by endothelial basement membrane reactivity. Rat kidney section. Hiatus hernia serum. × 172 . 


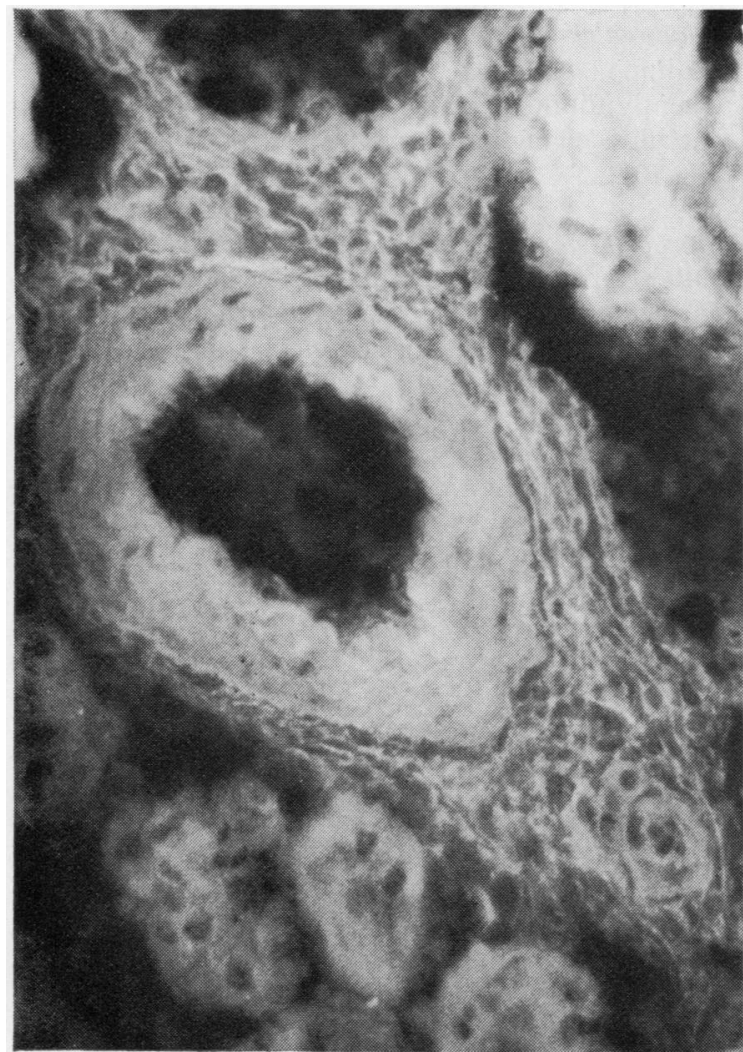

Fig 3

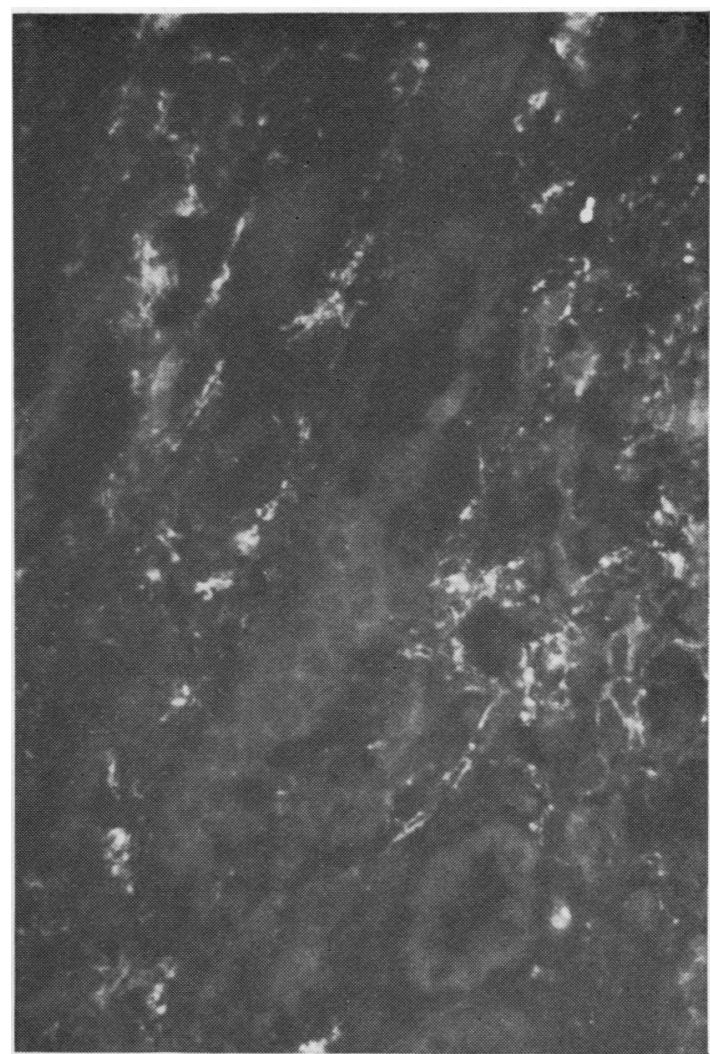

Fig 4

Fig 3 Staining of loose perivascular connective tissue in the adventitia of a renal artery. Rat kidney section. Rheumatoid arthritis serum. $\times 300$.

Fig 4 Renal medulla with perivascular specificity reacting with loose connective tissue around small blood vessels. Rat kidney section. Rheumatoid arthritis serum. $\times 300$.

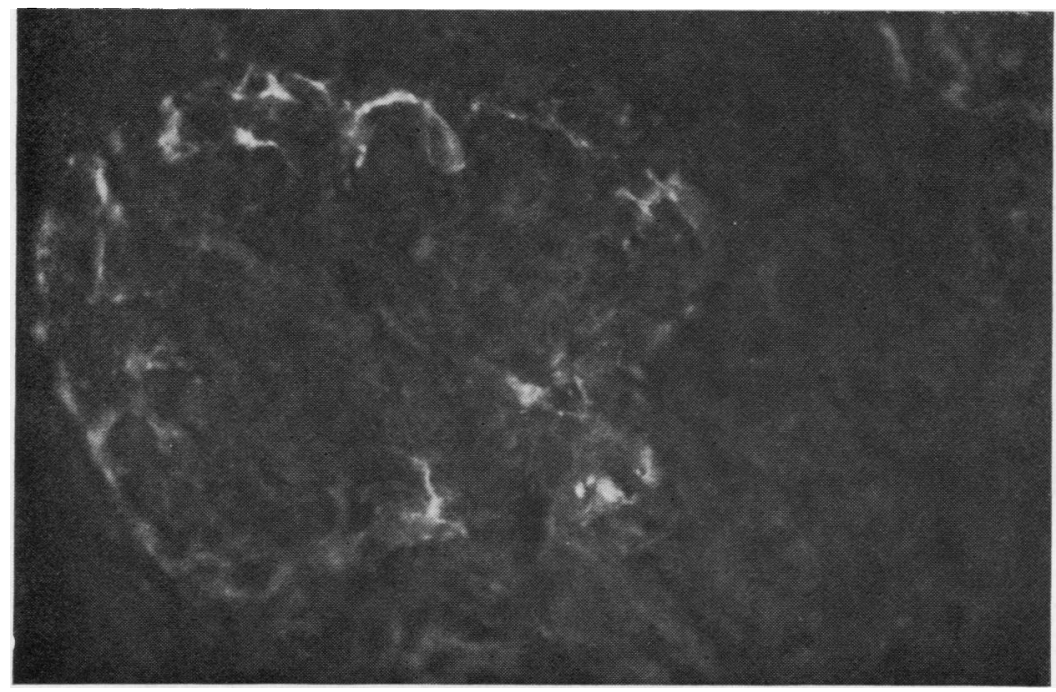

Fig 5 Epithelial basement membrane specificity, reacting only with the visceral layer of Bowman's capsule. Rat kidney section. Rheumatoid arthritis serum (also used on spleen section in fig 1). $\times 600$. 
et al (1962) described the parietal cell antibody, and Beck (1963) described the nuclear antibodies.

\section{GROUP 3 OTHER LESS WELL RECOGNIZED REACTIVITIES}

\section{Peripheral Nerve}

Certain sera gave the characteristic staining of peripheral nerve, and this was well seen in kidney sections where nerves run in association with blood vessels (fig 8). When rat brain sections were used the reactivity was invariably localized to the white matter.

\section{Epithelial Lining Cells}

The epithelial lining cells of the renal pelvis were frequently stained (fig 9) and this was often associated with staining of the basal layer of squamous epithelium and of salivary duct cells.

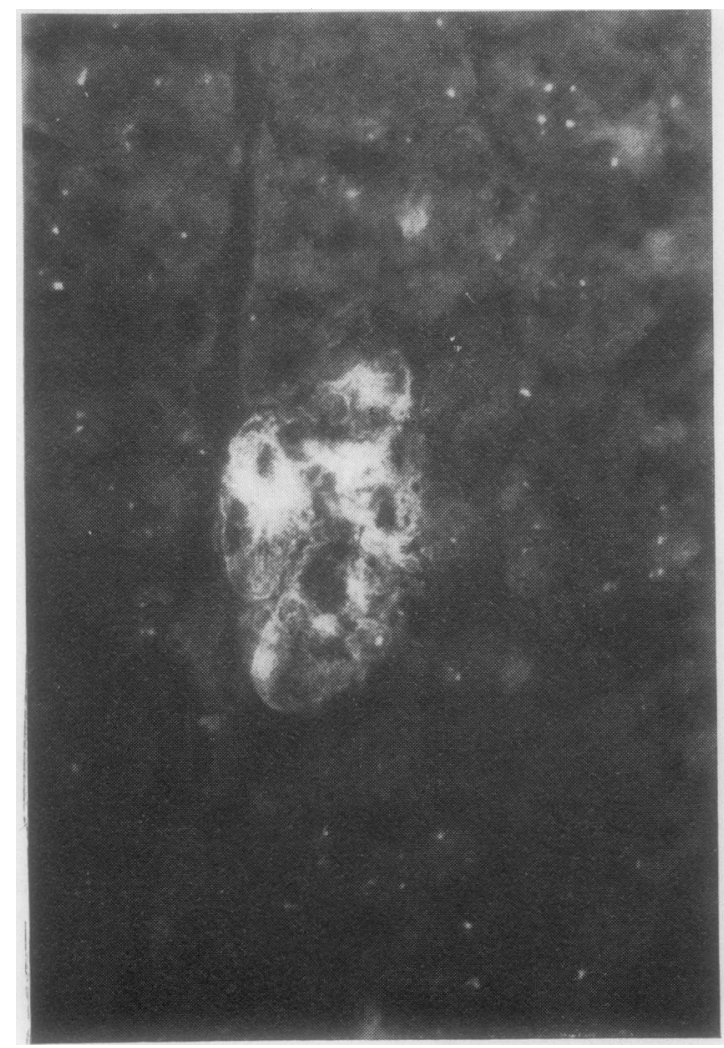

Fig 6

\section{Glomerular Mesangial Cells}

Staining, probably of mesangial cells, was frequently found limited to areas within the renal glomerulus, giving a rather linear or reticulated pattern (fig 10).

\section{Intracellular Ductules and Cell Membrane}

Other types of membranous and interstitial staining were seen and included reactions to cell membrane and intracellular ductules as seen in salivary gland (fig 11).

\section{Cells of the Renal Pyramid}

Not infrequently a reactivity was found which gave an homogeneous cytoplasmic staining of the cells of the rat renal pyramid (fig 12).

\section{Salivary Duct (Granular Stain)}

Sections of salivary gland often showed a bright

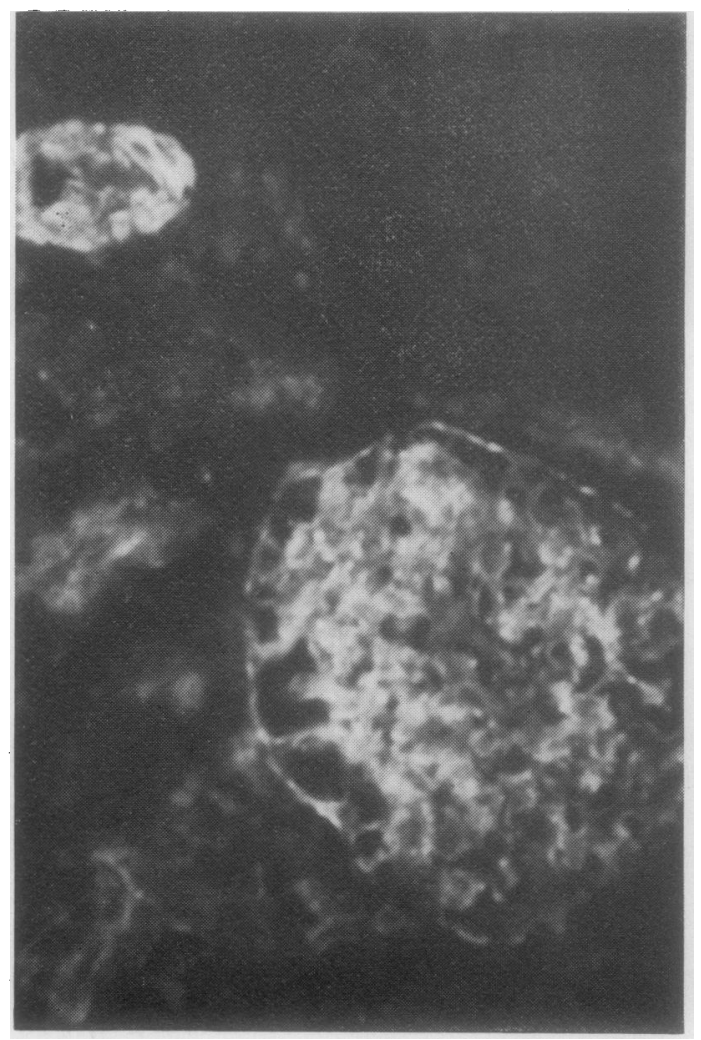

Fig 7

Fig 6 Epithelial basement membrane reactivity on rat salivary gland. Only occasional cells are specifically stained. Rheumatoid arthritis serum. $\times 300$.

Fig 7 'Glomerular' antibody, both basement membranes, and cellular elements of renal glomerulus are stained. Note smooth muscle staining of blood vessel wall (upper right). Rat kidney section. Chronic active hepatitis serum. $\times 375$. 


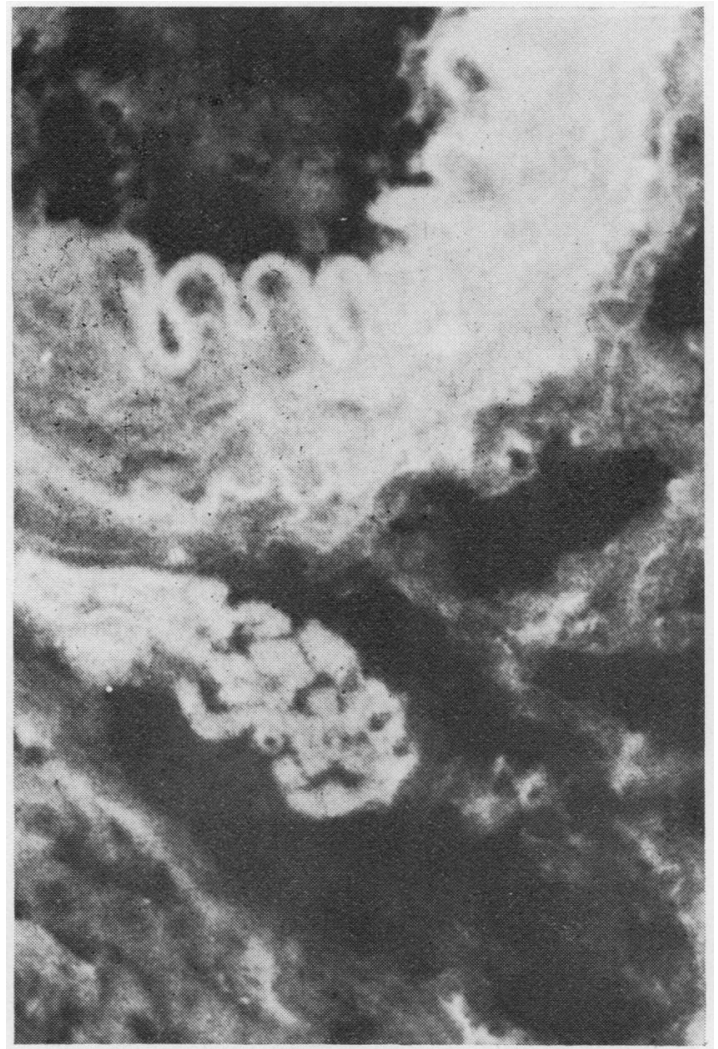

Fig 8

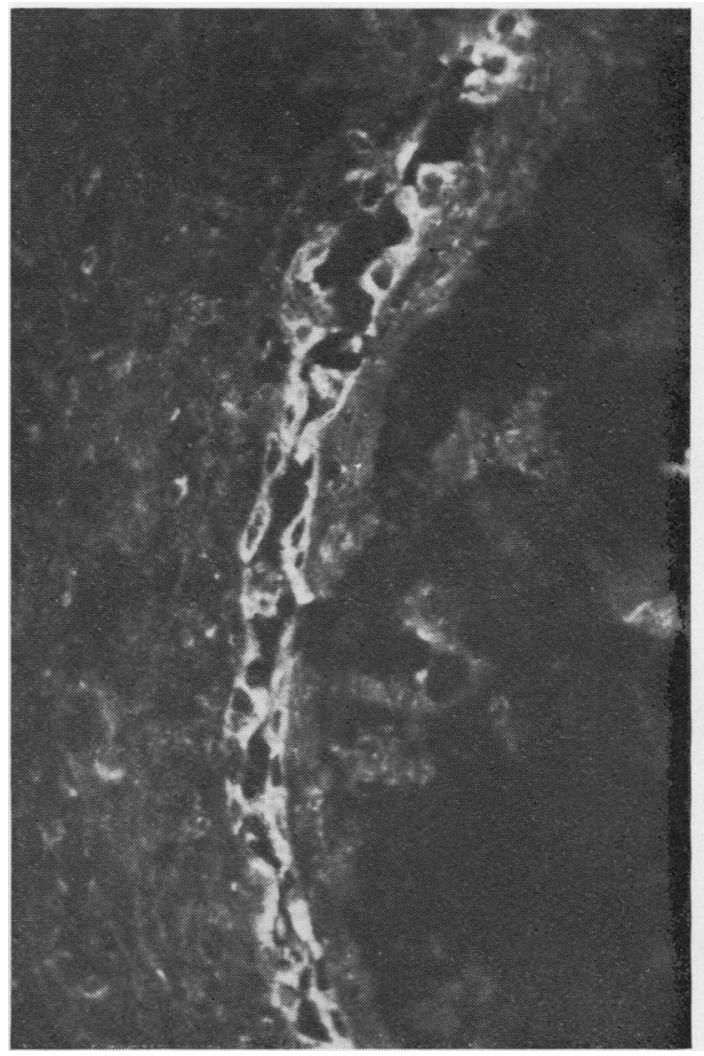

Fig 9

Fig 8 Section of rat kidney showing specific fluorescence of a peripheral nerve (left centre). The accompanying renal artery (lumen to the right) shows considerable autofluorescence. Rheumatoid arthritis serum. $\times 600$.

Fig 9 Cytoplasmic staining of epithelial cells lining the renal pelvis. Rat kidney section. Rheumatoid arthritis serum. $\times 375$.

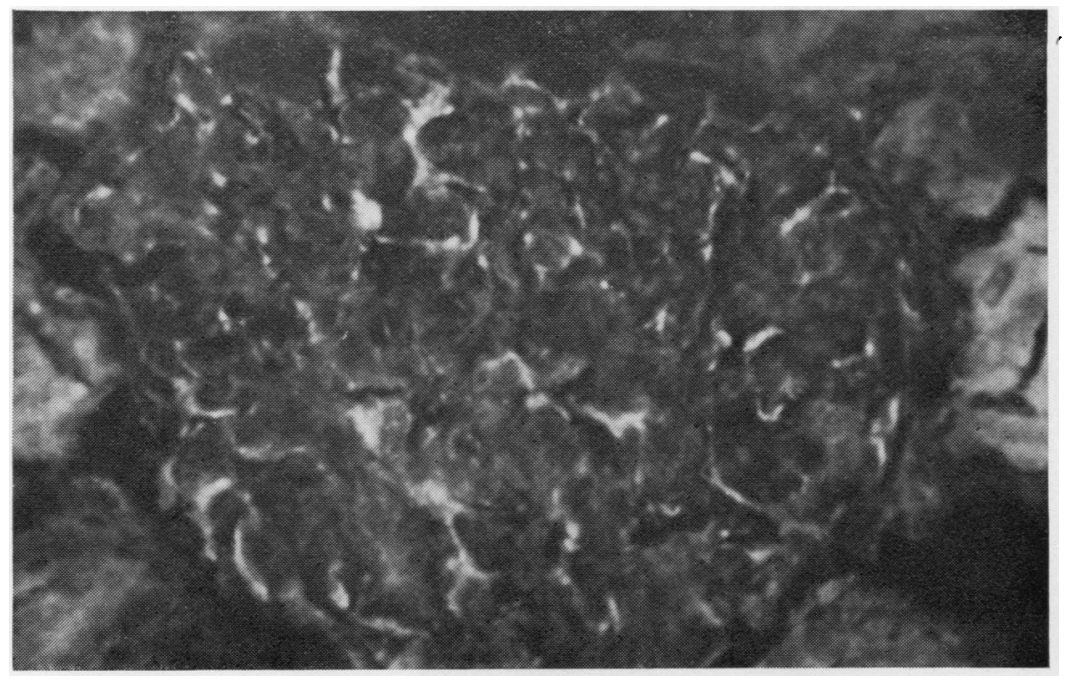

Fig 10 Specific fluorescence of cells in the rat renal glomerulus, probably mesangial cells. Glomerulonephritis serum. $\times 600$. 
N. Williamson, P. Asquith, P. L. Stokes, A. W. Jowett, and W. T. Cooke
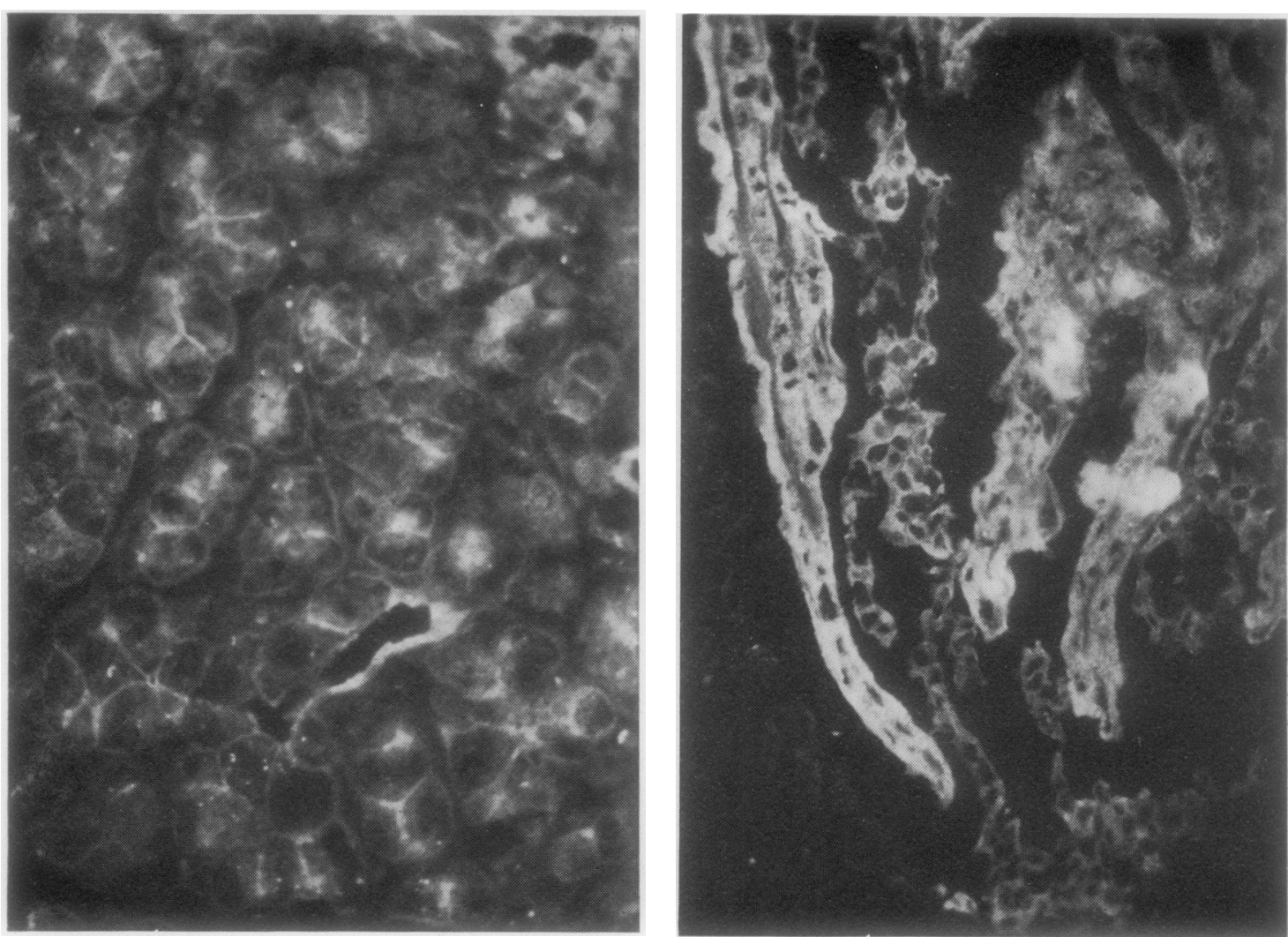

Fig 11

Fig 12

Fig 11 A reactivity with cell membranes and intracellular ductules of rat salivary gland. Carcinoma of lung serum. $\times 300$.

Fig 12 Homogeneous cytoplasmic staining of cells at tip of renal pyramid. Nuclei are unstained. There was no staining in adjoining tissue (top left). Rat kidney section. Myasthenia gravis serum. $\times 225$.

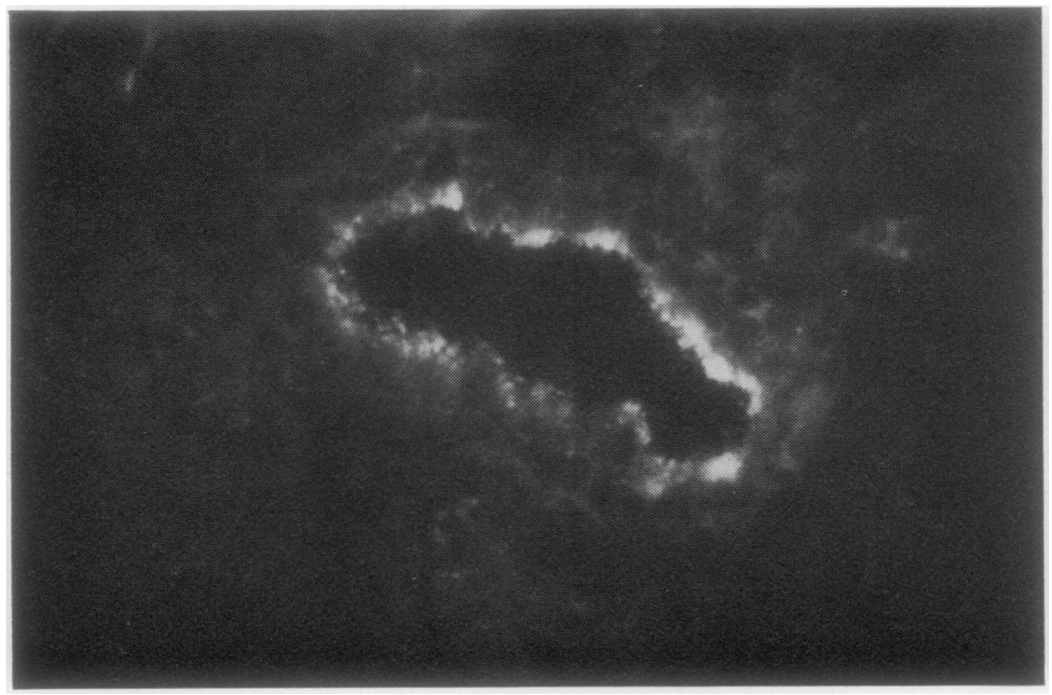

Fig 13 Section of rat $\mathcal{N}$ salivary gland with granular $N$ staining at the apices of the salivary duct cells. Hiatus hernia serum. $\times 712$. 
granular staining of the duct system (fig 13). Most of the staining was located in the apex of the cells near to the lumen of the duct.

\section{INCIDENCE OF DIFFERENT SPECIFICITIES}

\section{Group 1 Specificities}

The incidence of the 'antireticulin' reactivities, namely, those reacting against endothelial basement membrane, perivascular connective tissue, epithelial basement membrane, and the 'glomerular' staining, are shown independently in table I, and when two of these reactivities are combined in table II. The endothelial basement membrane reactivity was found alone in $22 \%$ of patients with coeliac disease, in $9 \%$ of hospital inpatients, and in only $2 \%$ of normal blood donors, However, if this reactivity is scored as positive, whether it is found alone or in combination with the perivascular reactivity, then the figures become $30 \%, 11 \%$, and $2 \%$ respectively.

The perivascular connective tissue reactivity, on the other hand, seems to be found in approximately equal proportions in the three groups of individuals. The epithelial basement membrane reactivity was found in a relatively high proportion of patients with rheumatoid arthritis (234 out of 634 patients (37\%)) but in only few of other diseases tested (15 out of the remaining 1170 patients $(1 \cdot 3 \%)$ ).

\begin{tabular}{|c|c|c|c|c|c|c|c|c|c|}
\hline \multirow[t]{2}{*}{ Diagnosis } & \multirow[t]{2}{*}{ No. } & \multicolumn{2}{|c|}{$\begin{array}{l}\text { Endothelial } \\
\text { Basement } \\
\text { Membrane }\end{array}$} & \multicolumn{2}{|c|}{$\begin{array}{l}\text { Perivascular } \\
\text { Connective } \\
\text { Tissue }\end{array}$} & \multicolumn{2}{|c|}{$\begin{array}{l}\text { Epithelial } \\
\text { Basement } \\
\text { Membrane }\end{array}$} & \multicolumn{2}{|c|}{$\begin{array}{l}\text { 'Glomerular } \\
\text { Antibody' }\end{array}$} \\
\hline & & No & $\%$ & No & $\%$ & No & $\%$ & No & $\%$ \\
\hline $\begin{array}{l}\text { Normal blood donors } \\
\text { Matched coeliac disease } \\
\text { Matched controls } \\
\text { Coeliac disease }\end{array}$ & $\begin{array}{l}100 \\
110 \\
110\end{array}$ & $\begin{array}{r}2 \\
24 \\
10\end{array}$ & $\begin{array}{r}2 \\
22 \\
9\end{array}$ & $\begin{array}{l}1 \\
2 \\
5\end{array}$ & $\begin{array}{l}1 \\
2 \\
4\end{array}$ & $\begin{array}{l}0 \\
2 \\
1\end{array}$ & $\begin{array}{l}0 \\
2 \\
1\end{array}$ & $\begin{array}{l}0 \\
0 \\
6\end{array}$ & $\begin{array}{l}\mathbf{0} \\
\mathbf{0} \\
\mathbf{5}\end{array}$ \\
\hline $\begin{array}{l}\text { Normal diet } \\
\text { Gluten-free diet }\end{array}$ & $\begin{array}{l}42 \\
91\end{array}$ & $\begin{array}{l}13 \\
19\end{array}$ & $\begin{array}{l}31 \\
21\end{array}$ & $\begin{array}{l}2 \\
\mathbf{3}\end{array}$ & $\begin{array}{l}5 \\
3\end{array}$ & $\begin{array}{l}1 \\
2\end{array}$ & $\begin{array}{l}2 \\
2\end{array}$ & $\begin{array}{l}0 \\
1\end{array}$ & $\begin{array}{l}0 \\
1\end{array}$ \\
\hline $\begin{array}{l}\text { Crohn's disease } \\
\text { Ulcerative colitis } \\
\text { Hiatus hernia } \\
\text { Other gastrointestinal diseases }\end{array}$ & $\begin{array}{r}29 \\
8 \\
94 \\
31\end{array}$ & $\begin{array}{r}5 \\
0 \\
33 \\
4\end{array}$ & $\begin{array}{r}17 \\
0 \\
35 \\
13\end{array}$ & $\begin{array}{l}0 \\
1 \\
0 \\
1\end{array}$ & $\begin{array}{r}0 \\
13 \\
0 \\
3\end{array}$ & $\begin{array}{l}1 \\
1 \\
0 \\
0\end{array}$ & $\begin{array}{r}3 \\
13 \\
0 \\
0\end{array}$ & $\begin{array}{l}1 \\
0 \\
1 \\
0\end{array}$ & $\begin{array}{l}3 \\
0 \\
1 \\
0\end{array}$ \\
\hline $\begin{array}{l}\text { Rheumatoid arthritis } \\
\text { Systemic lupus erythematosus } \\
\text { Myasthenia gravis } \\
\text { Other connective tissue diseases }\end{array}$ & $\begin{array}{r}634 \\
30 \\
20 \\
182\end{array}$ & $\begin{array}{r}26 \\
1 \\
4 \\
5\end{array}$ & $\begin{array}{r}4 \\
3 \\
20 \\
3\end{array}$ & $\begin{array}{r}10 \\
0 \\
1 \\
8\end{array}$ & $\begin{array}{l}2 \\
0 \\
5 \\
4\end{array}$ & $\begin{array}{r}234 \\
0 \\
0 \\
5\end{array}$ & $\begin{array}{r}37 \\
0 \\
0 \\
3\end{array}$ & $\begin{array}{r}12 \\
0 \\
2 \\
9\end{array}$ & $\begin{array}{r}2 \\
0 \\
10 \\
5\end{array}$ \\
\hline $\begin{array}{l}\text { Chronic active hepatitis } \\
\text { Other liver disorders }\end{array}$ & $\begin{array}{l}32 \\
78\end{array}$ & $\begin{array}{l}4 \\
8\end{array}$ & $\begin{array}{l}13 \\
10\end{array}$ & $\begin{array}{l}\mathbf{0} \\
\mathbf{2}\end{array}$ & $\begin{array}{l}\mathbf{0} \\
\mathbf{3}\end{array}$ & $\begin{array}{l}\mathbf{0} \\
\mathbf{0}\end{array}$ & $\begin{array}{l}\mathbf{0} \\
\mathbf{0}\end{array}$ & $\begin{array}{l}7 \\
9\end{array}$ & $\begin{array}{l}22 \\
12\end{array}$ \\
\hline Miscellaneous disorders & 303 & 17 & 6 & 14 & 5 & 5 & 2 & 5 & 2 \\
\hline
\end{tabular}

Table I Number and percentage of individuals showing 'antireticulin' reactivity occurring independently

\begin{tabular}{|c|c|c|c|c|c|c|c|}
\hline \multirow[t]{2}{*}{ Diagnosis } & \multirow[t]{2}{*}{ No } & \multicolumn{2}{|c|}{$\begin{array}{l}\text { Perivascular }+ \\
\text { Endothelial } \\
\text { Basement } \\
\text { Membrane }\end{array}$} & \multicolumn{2}{|c|}{$\begin{array}{l}\text { Perivascular + } \\
\text { Epithelial } \\
\text { Basement } \\
\text { Membrane }\end{array}$} & \multicolumn{2}{|c|}{$\begin{array}{l}\text { Perivascular + } \\
\text { 'Glomerular } \\
\text { Antibody' }\end{array}$} \\
\hline & & No & $\%$ & No & $\%$ & No & $\%$ \\
\hline $\begin{array}{l}\text { Normal blood donors } \\
\text { Matched coeliac disease } \\
\text { Matched controls } \\
\text { Coeliac disease }\end{array}$ & $\begin{array}{l}100 \\
110 \\
110\end{array}$ & $\begin{array}{l}0 \\
9 \\
2\end{array}$ & $\begin{array}{l}\mathbf{0} \\
\mathbf{8} \\
\mathbf{2}\end{array}$ & $\begin{array}{l}0 \\
1 \\
2\end{array}$ & $\begin{array}{l}\mathbf{0} \\
\mathbf{1} \\
\mathbf{2}\end{array}$ & $\begin{array}{l}\mathbf{0} \\
\mathbf{0} \\
\mathbf{2}\end{array}$ & $\begin{array}{l}\mathbf{0} \\
\mathbf{0} \\
\mathbf{2}\end{array}$ \\
\hline $\begin{array}{l}\text { Normal diet } \\
\text { Gluten-free diet }\end{array}$ & $\begin{array}{l}42 \\
91\end{array}$ & $\begin{array}{l}3 \\
6\end{array}$ & $\begin{array}{l}7 \\
6\end{array}$ & $\begin{array}{l}1 \\
0\end{array}$ & $\begin{array}{l}2 \\
0\end{array}$ & $\begin{array}{l}\mathbf{0} \\
\mathbf{0}\end{array}$ & $\begin{array}{l}\mathbf{0} \\
\mathbf{0}\end{array}$ \\
\hline $\begin{array}{l}\text { Crohn's disease } \\
\text { Ulcerative colitis } \\
\text { Hiatus hernia } \\
\text { Other gastrointestinal diseases }\end{array}$ & $\begin{array}{r}29 \\
8 \\
94 \\
31\end{array}$ & $\begin{array}{l}\mathbf{0} \\
\mathbf{0} \\
\mathbf{0} \\
\mathbf{1}\end{array}$ & $\begin{array}{l}\mathbf{0} \\
\mathbf{0} \\
\mathbf{0} \\
\mathbf{3}\end{array}$ & $\begin{array}{l}\mathbf{0} \\
\mathbf{0} \\
\mathbf{0} \\
\mathbf{0}\end{array}$ & $\begin{array}{l}\mathbf{0} \\
\mathbf{0} \\
\mathbf{0} \\
\mathbf{0}\end{array}$ & $\begin{array}{l}\mathbf{0} \\
\mathbf{0} \\
\mathbf{0} \\
\mathbf{0}\end{array}$ & $\begin{array}{l}\mathbf{0} \\
\mathbf{0} \\
\mathbf{0} \\
\mathbf{0}\end{array}$ \\
\hline $\begin{array}{l}\text { Rheumatoid arthritis } \\
\text { Systemic lupus erythematosus } \\
\text { Myasthenia gravis } \\
\text { Other connective tissue diseases }\end{array}$ & $\begin{array}{r}634 \\
30 \\
20 \\
182\end{array}$ & $\begin{array}{l}2 \\
0 \\
1 \\
0\end{array}$ & $\begin{array}{l}0.3 \\
0 \\
5 \\
0\end{array}$ & $\begin{array}{r}24 \\
0 \\
0 \\
2\end{array}$ & $\begin{array}{l}4 \\
0 \\
0 \\
1\end{array}$ & $\begin{array}{l}\mathbf{0} \\
\mathbf{0} \\
\mathbf{0} \\
\mathbf{1}\end{array}$ & $\begin{array}{l}0 \\
0 \\
0 \\
0.5\end{array}$ \\
\hline $\begin{array}{l}\text { Chronic active hepatitis } \\
\text { Other liver disorders }\end{array}$ & $\begin{array}{l}32 \\
78\end{array}$ & $\begin{array}{l}\mathbf{0} \\
\mathbf{0}\end{array}$ & $\begin{array}{l}\mathbf{0} \\
\mathbf{0}\end{array}$ & $\begin{array}{l}\mathbf{0} \\
\mathbf{0}\end{array}$ & $\begin{array}{l}\mathbf{0} \\
\mathbf{0}\end{array}$ & $\begin{array}{l}\mathbf{0} \\
\mathbf{0}\end{array}$ & $\begin{array}{l}\mathbf{0} \\
\mathbf{0}\end{array}$ \\
\hline Miscellaneous disorders & 303 & 4 & 1 & $\mathbf{0}$ & $\mathbf{0}$ & 1 & 0.3 \\
\hline
\end{tabular}

Table II Number and percentage of individuals showing 'antireticulin' reactivity occurring in combination 
Group 2 Specificities

Table III shows the incidence of smooth muscle antibody, mitochondrial antibody, parietal cell antibody, and nuclear antibodies.

Many of the inpatient control group were suffering from either connective tissue or liver diseases, and because of this the antinuclear antibodies and smooth muscle antibodies were found in relatively high proportions $(18 \%$ and $12 \%$ respectively), compared with $8 \%$ and $3 \%$ of patients with coeliac disease and only $0 \%$ and $1 \%$ of the normal blood donors. The predominant type of antinuclear anti- of body staining seen in patients with coeliac disease $\bar{\sigma}$ was the homogeneous type.

Group 3 Specificities

Table IV shows the distribution of reactivity with peripheral nerve, epithelial lining cells, glomerular

\begin{tabular}{|c|c|c|c|c|c|c|c|c|c|c|c|c|c|c|}
\hline \multirow[t]{3}{*}{ Diagnosis } & \multirow[t]{3}{*}{ No } & \multirow{2}{*}{\multicolumn{2}{|c|}{$\begin{array}{l}\text { Smooth } \\
\text { Muscle }\end{array}$}} & \multirow{2}{*}{\multicolumn{2}{|c|}{$\begin{array}{l}\text { Mitochon- } \\
\text { dria }\end{array}$}} & \multirow{2}{*}{\multicolumn{2}{|c|}{$\begin{array}{l}\text { Parietal } \\
\text { Cell }\end{array}$}} & \multirow{2}{*}{\multicolumn{2}{|c|}{ Nuclei }} & \multicolumn{5}{|c|}{ Nuclear Stain (number) } \\
\hline & & & & & & & & & & \multirow{2}{*}{$\begin{array}{l}\text { Homo- } \\
\text { geneous }\end{array}$} & \multirow{2}{*}{ Speckled } & \multirow{2}{*}{ Peripheral } & \multirow{2}{*}{$\begin{array}{l}\text { Reticu- } \\
\text { lated }\end{array}$} & \multirow{2}{*}{ Nucleolar } \\
\hline & & No & $\%$ & No & $\%$ & No & $\%$ & No & $\%$ & & & & & \\
\hline $\begin{array}{l}\text { Normal blood donors } \\
\text { Matched coeliac }\end{array}$ & 100 & 1 & 1 & 0 & 0 & 6 & 6 & 0 & 0 & 0 & 0 & 0 & 0 & 0 \\
\hline disease & 110 & 3 & 3 & 2 & 2 & 10 & 9 & 9 & 8 & 5 & 1 & 1 & 1 & 1 \\
\hline Matched controls & 110 & 13 & 12 & 2 & 2 & 13 & 12 & 20 & 18 & 13 & 3 & 2 & 1 & 1 \\
\hline $\begin{array}{l}\text { Normal diet } \\
\text { Gluten-free diet }\end{array}$ & $\begin{array}{l}42 \\
91\end{array}$ & $\begin{array}{l}2 \\
3\end{array}$ & $\begin{array}{l}5 \\
3\end{array}$ & $\begin{array}{l}1 \\
1\end{array}$ & $\begin{array}{l}2 \\
1\end{array}$ & $\begin{array}{l}4 \\
7\end{array}$ & $\begin{array}{r}10 \\
8\end{array}$ & $\begin{array}{r}0 \\
11\end{array}$ & $\begin{array}{r}0 \\
12\end{array}$ & $\begin{array}{l}0 \\
6\end{array}$ & $\begin{array}{l}0 \\
1\end{array}$ & $\begin{array}{l}0 \\
1\end{array}$ & $\begin{array}{l}0 \\
2\end{array}$ & $\begin{array}{l}0 \\
1\end{array}$ \\
\hline $\begin{array}{l}\text { Crohn's disease } \\
\text { Ulcerative colitis } \\
\text { Hiatus hernia }\end{array}$ & $\begin{array}{r}29 \\
8 \\
94\end{array}$ & $\begin{array}{l}5 \\
1 \\
2\end{array}$ & $\begin{array}{r}17 \\
13 \\
2\end{array}$ & $\begin{array}{l}1 \\
0 \\
1\end{array}$ & $\begin{array}{l}3 \\
0 \\
1\end{array}$ & $\begin{array}{l}7 \\
1 \\
3\end{array}$ & $\begin{array}{r}24 \\
13 \\
3\end{array}$ & $\begin{array}{l}2 \\
2 \\
9\end{array}$ & $\begin{array}{r}7 \\
25 \\
10\end{array}$ & $\begin{array}{l}1 \\
1 \\
5\end{array}$ & $\begin{array}{l}0 \\
1 \\
2\end{array}$ & $\begin{array}{l}1 \\
0 \\
1\end{array}$ & $\begin{array}{l}0 \\
0 \\
0\end{array}$ & $\begin{array}{l}0 \\
0 \\
1\end{array}$ \\
\hline $\begin{array}{l}\text { Other gastrointestinal } \\
\text { diseases }\end{array}$ & 31 & 4 & 13 & 2 & 6 & 6 & 19 & 4 & 13 & 2 & 1 & 0 & 1 & 0 \\
\hline $\begin{array}{l}\text { Rheumatoid arthritis } \\
\text { Systemic lupus }\end{array}$ & 634 & 46 & 7 & 4 & 1 & 46 & 7 & 156 & 25 & 98 & 40 & 10 & 6 & 2 \\
\hline erythematosus & 30 & 1 & 3 & 0 & 0 & 2 & 6 & 30 & 100 & 15 & 2 & 12 & 1 & 0 \\
\hline Myasthenia gravis & 20 & 1 & 5 & 0 & 0 & 5 & 25 & 1 & 5 & 1 & 0 & 0 & 0 & 0 \\
\hline $\begin{array}{l}\text { Other connective } \\
\text { tissue diseases }\end{array}$ & 182 & 23 & 13 & 6 & 3 & 16 & 9 & 34 & 19 & 18 & 7 & 2 & 4 & 3 \\
\hline $\begin{array}{l}\text { Chronic active } \\
\text { hepatitis } \\
\text { Other liver disorders }\end{array}$ & $\begin{array}{l}32 \\
78\end{array}$ & $\begin{array}{l}20 \\
17\end{array}$ & $\begin{array}{l}63 \\
22\end{array}$ & $\begin{array}{l}7 \\
4\end{array}$ & $\begin{array}{r}22 \\
5\end{array}$ & $\begin{array}{r}6 \\
11\end{array}$ & $\begin{array}{l}19 \\
14\end{array}$ & $\begin{array}{l}14 \\
12\end{array}$ & $\begin{array}{l}44 \\
15\end{array}$ & $\begin{array}{r}10 \\
5\end{array}$ & $\begin{array}{l}1 \\
5\end{array}$ & $\begin{array}{l}2 \\
2\end{array}$ & $\begin{array}{l}1 \\
0\end{array}$ & $\begin{array}{l}0 \\
0\end{array}$ \\
\hline $\begin{array}{l}\text { Miscellaneous } \\
\text { disorders }\end{array}$ & 303 & 12 & 4 & 2 & 0.7 & 34 & 11 & 33 & 11 & 20 & 9 & 1 & 1 & 2 \\
\hline
\end{tabular}

Table III Number and percentage of individuals showing well recognized antibodies to cellular and subcellular components (group 2)

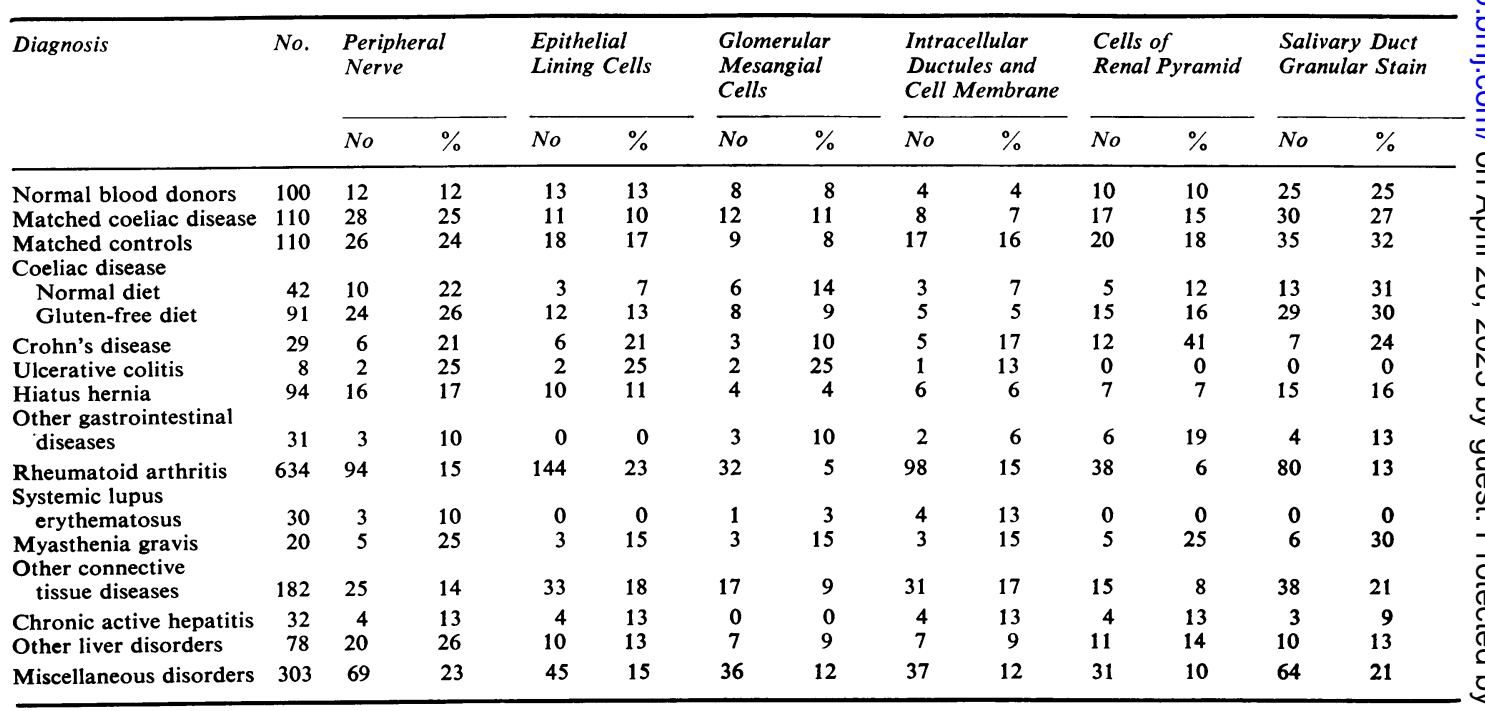

Table IV Number and percentage of individuals showing other less well recognized reactivities (group 3 ) 
mesangial cells, intracellular ductules and cell membrane, and cells of the renal pyramid and salivary duct (granular stain). There was some difference in incidence of these specificities between the various groups of individuals but these were not considered to be biologically significant.

\section{EFFECT OF DIET}

Patients with coeliac disease on a normal diet showed a marginally higher incidence of 'antireticulin' reactivities over patients on a gluten-free diet, $47 \%$ and $31 \%$ respectively. If the endothelial basement membrane reactivity alone is considered then this shows $31 \%$ and $21 \%$ respectively. When six patients changed from a normal to a gluten-free diet, the endothelial basement membrane activity remained positive in three, was altered from positive to negative in two, and from negative to positive in one. When two patients on a gluten-free diet were changed to a normal diet, both developed weakly positive reactivities.

Of the six patients who changed from a normal to gluten-free diet, one developed a positive antinuclear antibody (reticulated stain). Antinuclear antibodies were found in 11 of the 92 coeliac disease patients on a gluten-free diet, but not at all in the 42 patients on a normal diet.

\section{Discussion}

Reticulin is a term used by histologists to describe a group of thin high-branched fibres in connective tissue, staining black with silver impregnation, magenta with periodic acid-Schiff, red with sulphation-metachromasia, and remaining essentially unstained by the van Gieson method (Pearse, 1960). Some of these staining methods in addition to staining reticulin also react with basement membranes, especially epithelial basement membranes, suggesting that these may be closely related chemically.

Immunologically reticulin and the basement membranes share many antigenic components, but they also possess others which are unique to the individual tissue. It is presumably these unique components which give rise to the specific staining patterns in different disease entities. Attempts to isolate these antigenic components and to prepare antisera to these has proved to be technically difficult (Scott and Rowell, 1967). Consequently, until these various antigenic components are characterized by isolation and purification, the exact specificities of the socalled antireticulin antibodies occurring in, for example, coeliac disease cannot be defined. Presumably it is for this reason that a generic term 'antireticulin antibody' had evolved. Such difficulties are not unique, and the term 'antinuclear antibodies' is often used without reference to the exact staining pattern seen. However, positive antinuclear staining can occur in many connective tissue diseases, whereas antibodies to native (double strand) deoxyribonucleic acid are almost diagnostic of systemic lupus erythematosus.

In this study there was considerable variation in the patterns of staining found, and at least four distinct specificities were observed among sera reacting with material identifiable on histological examination as reticulin. Of these specificities, only that reacting with endothelial basement membrane appeared to be significantly increased in the serum of patients with coeliac disease. Rizzetto and Doniach (1973) recognized five 'reticulin' antibodies: of these, $R_{1}$ is comparable to what is here called the endothelial basement membrane reactivity; $\mathbf{R}_{2}$ to that described as the perivascular connective tissue reactivity; and $\mathbf{R}_{5}$ corresponds in this study to the finding of sera showing more than one specificity. It was not possible to compare the $\mathbf{R}_{\mathbf{3}}$ and $\mathbf{R}_{\mathbf{4}}$ antibodies because these related to staining in rat liver, a tissue which was not used in the present study.

The endothelial basement membrane reactivity should be distinguished from the specificity found frequently in rheumatoid arthritis reacting predominantly against epithelial basement membrane. This epithelial basement membrane reactivity was first called a 'reticulin' antibody by Williamson et al (1966) but was later modified by them when another 'reticulin' antibody, which reacted with endothelial basement membrane, was discovered in a patient with myasthenia gravis (Williamson et al, 1967). Furthermore, patients with hiatus hernia also develop reactivity to endothelial basement membrane (Collis, 1970) which is identical in nature to the major specificity type found in coeliac disease.

The reason for the appearance of endothelial basement membrane specificity in coeliac disease is not known. The reactivity has some of the characteristics of an auto-antibody and hence its occurrence in coeliac disease might suggest that this is an autoimmune disease. Some indirect support for this theory is provided by the occurrence of this same reactivity in myasthenia gravis, a disease which has many of the hallmarks of an auto-immune disease. On the other hand, this specificity has also been demonstrated in patients with hiatus hernia, which is unlikely to be involved with auto-immunity. Seah et al (1971a) considered this specificity to be diagnostic for coeliac disease. However, its occurrence in less than $50 \%$ of adults with coeliac disease and its occurrence in non-coeliac gastrointestinal and other diseases makes this unlikely. Nevertheless the study of Magalhaes et al (1974) suggests that, whereas IgG class connective tissue specificities are not disease 
specific, IgA class specificities occur only in coeliac disease. Alp and Wright (1971) thought a possible explanation for the connective tissue reactivity was the absorption of reticulin antigens in the diet through the mucosa damaged by gluten. The occurrence of connective tissue specificities in the sera of patients with both myasthenia gravis and oesophageal disease could be explained on a similar basis as it is possible that dietary antigens including reticulin could regurgitate into the oesophagus and then into the lungs to evoke an antireticulin response. Alp and Wright (1971) also considered that the antireticulin specificity could result from cross reactivity of dietary antigens, especially gluten, with endogenous reticulin. In this respect it is interesting that Seah et al (1972) reported that they were able to remove 'antireticulin' reactivity from the sera of patients with dermatitis herpetiformis using gluten. However, this was not confirmed in the recent studies of Brown et al (1973) and Magalhaes et al (1974) and in a separate study by Asquith et al (unpublished).

Alp and Wright (1971), Seah et al (1971b), von Essen et al (1972), and Magalhaes et al (1974) recorded a higher incidence of antireticulin antibodies in coeliac patients on normal diets than in patients on gluten-free diets. Alp and Wright (1971) also showed the reappearance of the antibodies following gluten challenge in children, whereas in adults Magalhaes et al (1974) showed no serum antibody response following a single $30 \mathrm{~g}$ gluten challenge. In the present study the incidence of antireticulin specificities in coeliac disease patients on normal diets was only marginally higher than in those on a gluten-free diet, and gluten challenge in the two cases tested stimulated only weak reactions.

One other observed effect of diet, not previously recorded, was the presence of antinuclear antibodies in coeliac disease patients on a gluten-free diet, and conversion from negative on a normal diet to positive on a gluten-free diet was seen in one patient. If the presence of antireticulin specificities in coeliac disease was due to an anamnestic response to bacterial and nutritional antigens, as postulated by Rizzetto and Doniach (1973), then it would be reasonable to expect the incidence of antinuclear antibodies and other auto-antibodies to be increased more in patients on a normal diet than in those on a gluten-free diet. In fact the opposite seems to be the case, some antibodies increasing after withdrawal of gluten.

We wish to thank Mr R. Drew and Dr D. Catty for the monospecific antihuman IgG antiserum and Mrs C. Hall and Mrs H. Walker for expert technical assistance.

\section{References}

Alp, M. H. and Wright, R. (1971). Autoantibodies to reticulin in patients with idiopathic steatorrhoea, coeliac disease, and Crohn's disease, and their relation to immunoglobulins and dietary antibodies. Lancet, 2, 682-685.

Ammann, A. J. and Hong, R. (1971). Unique antibody to basement membrane in patients with selective $\operatorname{IgA}$ deficiency and coeliac disease. Lancet, 1, 1264-1266.

Beck, J. S. (1963). Auto-antibodies to cell nuclei. iScot. med. J., 8, 373-388.

Brown, I. L., Ferguson, A., Carswell, F., Horne, C. H. W., and MacSween, R. N. M. (1973). Autoantibodies in children with coeliac disease. Clin. exp. Immunol., 13, 373382.

Collis, J. L. (1970). The causes of the variable response to gastric reflux in hiatus hernia. J. roy. Coll. Surg. Edinb., 15, 77-87.

von Essen, R., Savilahti, E., and Pelkonen, P. (1972). Reticulin antibody in children with malabsorption. Lancet, 1 , 1157-1159.

Johnson, G. D., Holborow, E. J., and Glynn, L. E. (1965). Antibody to smooth muscle in patients with liver disease. Lancet, 2, 878-879.

Magalhaes, A. F. N., Peters, T. J., and Doe, W. F. (1974). Studies on the nature and significance of connective tissue antibodies in adult coeliac disease and Crohn's disease. Gut, 15, 284-288.

Nairn, R. C., Ed. (1969). Fluorescent Protein Tracing, 3rd edition, pp. 303-307. Livingstone, Edinburgh.

Pearse, A. G. E. (1960). Histochemistry, Theoretical and Applied, 2nd edition, p. 154. Churchill, London.

Rizzetto, M. and Doniach, D. (1973). Types of 'reticulin' antibodies detected in human sera by immunofluorescence. J. clin. Path., 26, 841-851.

Scott, D. G. and Rowell, N. R. (1967). Alterations in the antigenic constitution of renal glomerular capillaries accompanying the histological maturation of renal glomeruli in the rat. Ann. rheum. Dis., 26, 10-17.

Seah, P. P., Fry, L., Hoffbrand, A. V., and Holborow, E. J. (1971a). Tissue antibodies in dermatitis herpetiformis and adult coeliac disease. Lancet, 1, 834-836.

Seah, P. P., Fry, L., Holborow, E. J., Rossiter, M. A., Doe, W. F., Magalhaes, A. F., and Hoffbrand, A. V. (1973). Antireticulin antibody: incidence and diagnostic significance. Gut, 14, 311-315.

Seah, P. P., Fry, L., Rossiter, M. A., Hoffbrand, A. V., and Holborow, E. J. (1971b). Anti-reticulin antibodies in childhood coeliac disease. Lancet, 2, 681-682.

Seah, P. P., Fry, L., Stewart, J. S., Chapman, B. L., Hoff brand, A. V., and Holborow, E. J. (1972). Immunoglobulins in the skin in dermatitis herpetiformis and coeliac disease. Lancet, 1, 611-614.

Taylor, K. B., Roitt, I. M., Doniach, D., Couchman, K. G., and Shapland, C. (1962). Autoimmune phenomena in pernicious anaemia: gastric antibodies. Brit. med. J., 2, 1347-1352.

Walker, J. G., Doniach, D., Roitt, I. M., and Sherlock, S. (1965). Serological tests in diagnosis of primary biliary cirrhosis. Lancet, 1, 827-831.

Whittingham, S., Mackay, I. R., and Irwin, J. (1966). Autoimmune hepatitis: immunofluorescence reactions with cytoplasm of smooth muscle and renal glomerular cells. Lancet, 1, 1333-1335.

Williamson, N., Housley, J., Hulme, A., and Wall, P. G. (1966). Autoimmune hepatitis. (Letter). Lancet, 2, 286.

Williamson, N., Housley, J., and McCormick, J. N. (1967). An antibody to renal glomeruli, synovial membrane, and reticulin found in rheumatoid arthritic sera. Ann. rheum. Dis., 26, 348-349. 